\title{
Healthier catering initiatives in London, UK: An effective tool for encouraging healthier consumption behaviour?
}

\begin{abstract}
The increasing amount of 'unhealthy' food consumed outside the home is thought to be a major contributory factor to growing levels of obesity. To tackle the problem and promote changes in catering and consumption behaviour, initiatives designed to encourage out-of-home caterers to provide healthier menus or adopt healthier cooking practices have been developed. Such voluntary agreements, rather than legislation, are the UK government's preferred strategy. This paper reports on and explores issues arising from an evaluation of one such initiative - the Healthier Catering Commitment, piloted with over 80 independent businesses in London in the UK. Analysis of data on take-up of the scheme, and interviews with businesses and those involved in assessing them against the scheme's criteria, suggests the extent to which businesses are prepared to make changes to their catering practices. Operational barriers as well as aspects of the local trading environment, are shown to impact on the level of business commitment to the initiative. In considering the degree to which the scheme's criteria inform, widen or restrict consumer choice, the paper adds to the debate on effective strategies for encouraging behaviour change. It also comments on the extent to which voluntary agreements are likely to be an effective means of ensuring a healthier food environment, and the extent to which government intervention is justified in the interests of improving public health and tackling health inequalities.
\end{abstract}

Keywords: consumption; healthy public policy; health inequalities

\section{Introduction}

The unhealthy nature of much of the food eaten outside the home has been identified as one of a number of key aspects of our modern-day lifestyle that is contributing to rising levels of obesity (Foresight 2007). Fast-food in particular has been highlighted because it tends to be more energy dense and has a higher fat content than meals prepared at home (Prentice and Jebb 2003). In addition the frequency with which it is consumed has been shown to be linked to increased body weight and obesity (Pereira et al. 2005). Of increasing policy concern is the extent to which obesity has been shown to be associated with social and economic deprivation across all age ranges (Marmot 2010). Research suggests that obesity may be more prevalent in areas with a high concentration of fast-food outlets (Currie et al. 2009, Fraser et al. 2010, De Vogli et al. 2011), and that outlets are often concentrated in areas of deprivation (McDonald et al. 2007, Pearce et al. 2007, Smoyer-Tonic et al. 2008, Fraser et al. 2010), thus linking fast-food consumption to debates regarding health inequalities and food security.

The term 'food security' has generally been defined as existing when all people have sufficient, safe and nutritious food to live an active healthy life (FAO 1996). It has until recently been seen as a concern confined to low income countries in the global south, but increasing food prices now mean that many poorer families in high income countries are forced to compromise on the quality and healthiness of food they buy (Dowler et al, 2011). The 2011 UK Family Food survey, for example, found that purchases of fruit and veg are on a downward trend, 10\% lower in 2011 than 2007, with those on lower incomes most likely to be purchasing less (Defra 2012). This tendency to trade down is also evidenced in eating-out behaviour. Recent research by the NPD ${ }^{i}$ 
group suggests that whilst there has been an overall decline in the number and value of meals eaten out of the home, fast-food is forming an increasing proportion of these outof-home meals, increasing from 47.3\% in 2007 to 50.4\% in 2011 (Wallop 2012).

In 2003 Coveney highlighted the need for a more coherent food policy for public health, noting that the dominant approach in health promotion has been to focus on health education and behaviour change to encourage healthy eating habits, rather than on more 'upstream' initiatives which might make it easier to access better and more affordable food. Nine years on, this is still largely the case. The latest report from the government's Obesity Policy team, Healthy Lives, Healthy People, states that (DoH 2011, p. 24) 'we will favour interventions that equip people to make the best possible choices for themselves, rather than removing choice or compelling change.' The focus instead is on making use of new ideas from the behaviour sciences and 'nudging' people in the direction of healthier life styles (DoH 2011), despite the marked lack of evidence to show that nudging approaches work in changing behaviour at a population level (House of Lords 2011). Thus as Gustafsson (2011, p. 386) notes, poor diet is seen as a result of consumers making poor choices rather than due to the quality of the supply chain. Instead of regulation the government is relying on a series of voluntary agreements (Responsibility Deals) with industry regarding the calorific labelling of food, reduction in salt and fat etc. This, despite the lack of evidence to suggest that actions such as calorific labelling or healthy eating guidelines will have a significant impact on consumption patterns (Ebel et al. 2009, Lindsay 2010, Chaufan et al. 2011). Furthermore, research suggests that consumers themselves believe that it is the responsibility of government, not just the individual, to ensure that healthy food is affordable and accessible to all (Dowler 2011).

National voluntary agreements with industry also tend to by-pass the smaller independent fast food outlets which tend to proliferate in deprived urban areas in particular (Seex 2007, Kwate 2008). Under the current government's new policy of devolving responsibility for much of public health, it is left to local administrations to develop policies regarding public health and the local food environment. The last government drew attention to the large number of fast-food outlets operating in local neighbourhoods, and, in its Healthy Weight Healthy Lives (2008) strategy, recommended that local authorities should 'use existing planning powers to control more carefully the number and location of fast food outlets in their local areas.' (Cross Government Obesity Unit 2008, p.18). A number of boroughs have successfully used this approach to restrict the opening of new fast-food outlets - particularly in areas close to schools (L.B. Waltham Forest 2008, L.B. Barking and Dagenham 2009). However, whilst a step in the right direction, such action does little to address the prevalence of existing unhealthy catering outlets. Persuading businesses involved in out-of-home catering to sell a range of healthier food offers an alternative or additional strategy. This is more in line with the current government's policy which suggests that local authorities should 'Work with local businesses and partners to increase access to healthy food choices.' (DoH 2011, p. 28). In pursuit of this agenda, a number of local authorities are adopting award schemes which are designed to encourage and promote those businesses offering healthier menus.

This paper is concerned with the different strategies these healthier catering award schemes can employ to encourage businesses to adopt healthier catering practices. It discusses the extent to which such interventions should be designed to inform and encourage healthier consumer choices (the UK government's preferred approach), or whether choices should be restricted in the interests of public health. Focusing particularly on the business perspective, it sets out to illustrate how 
operational issues and the local trading environment influence businesses' willingness to adopt these healthier practices. Thus the paper raises questions about choice and the extent to which government, or in this case businesses acting as ambassadors for government policy, are able or willing to intervene. To address these issues the paper draws on some of the findings from two evaluations of the Chartered Institute for Environmental Health's Healthier Catering Commitment (HCC) scheme recently piloted in London, in the UK. The HCC aims to encourage businesses in the catering trade to reduce the levels of saturated fat, salt and sugar in foods, offer healthier options and/or smaller portions, and adopt healthier cooking and preparation practices by using the 'small changes make a big difference' principle. It also aims to raise awareness of the importance of providing healthier food choices and ideally lead to changes in consumption behaviour. Thus the scheme is a means of engaging small independent catering outlets in the healthy catering policy agenda.

\section{The Healthier Catering Commitment Scheme}

The Healthier Catering Commitment (HCC) scheme follows on from a range of initiatives targeted at out-of-home caterers. These have involved campaigns on issues such as salt, and key food types such as chips and pizza, as well as more generic national and local healthier catering schemes (see LACORS 2010 for an outline of some of these). The widely-adopted national Heartbeat Award scheme targeted a broad range of catering establishments and was found to have generally had a limited positive impact on eating habits (Holdsworth et al. 2004, Thorogood 2007), but was felt by some authorities to be too inflexible and its criteria often beyond the reach of many fast-food businesses (CIEH 2004).

The Healthy Catering Commitment scheme by contrast is designed to be relatively easy for all types of catering establishments, including fast-food outlets, to sign up to, thereby encouraging take-up and providing a means of engaging businesses in the healthier catering agenda. Developed by the Chartered Institute for Environmental Health (CIEH), in conjunction with a London-wide network of Environmental Health Officers (EHOs), the scheme is designed to be implemented by EHOs, although in some boroughs support from nutritionists and other public health professionals is also available. To gain the Award, businesses need to meet a minimum of 8 criteria (from a list of 22) that include conditions in relation to the use of fats and oils, salt, sugar, milk and spreads, fruit and vegetables, portion size and promotion of healthier options. Four of the criteria concerning the type of oil used, use of salt, availability of diet drinks, and smaller portions, are essential criteria that all businesses must comply with. A further three concern the maintenance of cooking oil and are mandatory criteria for those involved in deep fat frying (See table 1). Some of the criteria involve eliminating choice, for example by switching to a healthier type of oil, while others require the business to offer a healthier default option or a healthier alternative - thereby leaving the choice to the customer. The scheme thus provides an interesting opportunity for exploring how such behaviour-change strategies work in practice.

\section{Methods}

The research included a pan-London study of boroughs and businesses adopting the scheme, and a separately commissioned, smaller, but more in-depth qualitative study in three west London boroughs which allowed for a more detailed understanding of the business perspective on the ease of adopting the required healthier changes. 
The pan-London study involved inviting all boroughs known to be operating the HCC scheme to enter data on each of the businesses in their area that had been awarded the HCC, into an online survey. This survey sought to capture information on the business (size, ethnicity of owner-manager, planning category of the premises) and the type of food sold. Details of the HCC criteria which each business had adopted before and after intervention, as well as those that the business did not want to comply with, and the total number of changes made, were also collected. The data were entered into the survey by those who had been directly involved in advising businesses on making the changes required to gain the award, and included 55 EHOs, 21 dieticians or nutritionists, and one external consultant. Useable data from a total of 77 businesses across 12 London boroughs was captured in this manner. The 12 boroughs included a mix of inner and outer London boroughs. The take-up of the criteria was analysed by business type using online survey software.

The second stage of the pan-London survey involved telephone or face-to-face interviews with the main person responsible for the implementation of the scheme in each borough. These interviews sought to develop a detailed understanding of the operation of the scheme in each area including the particular strategy and approach adopted, what worked well and why, key barriers that had prevented businesses from adopting particular healthier changes, issues regarding the criteria, and the borough's future plans regarding the scheme.

A more in-depth qualitative study in West London involved three boroughs, included in the pan-London study, who were keen to undertake a more detailed business-level evaluation of the operation of the scheme in their area. One of these boroughs targeted a relatively affluent ward (IMD ${ }^{\mathrm{ii}} 2010$ score 20.3), whilst the other two focused on areas with greater levels of deprivation (IMD 2010 scores of 24.59 and 27.89 respectively). This second study provided an opportunity for detailed interviews to be undertaken with the 10 businesses involved and 28 customers from five of these businesses. The interviews were designed to identify issues regarding the ease of making the healthier changes required and the extent to which these had been welcomed by customers. All the interviews were conducted on the business premises thus also allowing for observation of menus and food displays. Two focus groups with the EHOs, nutritionist, and public health practitioner involved in implementing the scheme were also held (one prior to the implementation of the HCC scheme and one after all 10 businesses had gained the award) to explore issues regarding the assessment of businesses against the HCC criteria and key barriers faced by businesses. This study provided a convenience sample of small size and is clearly not representative of London as a whole. However by capturing both quantitative and qualitative data from those implementing the scheme and those at the receiving end, the validity of the findings is enhanced. The quantitative pan-London data provided a measure of the level of acceptance or resistance to each of the healthier changes required to achieve the award, whilst the interviews with businesses and those involved in supporting them make the changes, provided insights into the reasons behind the relative acceptability of each change.

For both studies participants' informed consent was secured for the interviews and assurance given that confidentiality would be protected.

\section{Findings and key issues}

Table 1 provides data on the take-up of each of the criterion and the number of businesses making healthier changes to their menus or cooking practices as a result of adopting the HCC. The 77 businesses surveyed here only had to make an average of 2.56 changes to secure the HCC award, although as might be expected, hot food takeaway outlets had to make more changes than restaurants, but still only an average of 3.1 compared to 1.95 for restaurants. On the whole therefore the businesses surveyed here found the scheme relatively easy to adopt.

Table 1 also illustrates the level of intervention for each of the changes. The analysis which follows considers issues in relation to each of the different types of intervention strategies adopted by the scheme. 
Table 1 here

\section{Criteria involving the provision of information}

The results of the analysis of take-up of the HCC criteria show that changes which just entailed providing customers with information on healthier eating (criterion 22) were easiest for businesses to adopt. Table 1 shows that twenty-six businesses agreed to start promoting healthier eating as a result of the intervention. Two of those interviewed did this by producing a 'healthier menu' which highlighted those items on their existing menu which were agreed as being healthier options based on advice from the HCC scheme's nutritionist. The cost to the businesses of adopting this type of strategy only entailed the expense incurred in printing a separate menu. Customers found the information useful, but only three of the twelve surveyed stated that their reason for choosing the healthier dishes was because it was a 'healthier option'. For most (six customers) it was their 'usual choice', suggesting that the menu may not have had a great influence in changing consumption patterns.

\section{Criteria enabling choice}

Eleven of the $22 \mathrm{HCC}$ criteria (criteria 9 to 11 , and 14 to 21) involved providing customers with a range of healthier alternatives such as offering wholemeal varieties of pasta and rice, low-fat milk and spreads, and low-sugar drinks. The business interviews suggested that where both healthy and unhealthy alternatives could easily be sourced, offered, displayed and stored, these criteria were relatively straight forward for businesses to adopt. Health-conscious customers also appreciated the choice. It was noted, however, that the scheme was designed so that businesses were deemed to have met any one of these particular 'enabling choice' criteria as long as they provided a healthy alternative. Many did so but displayed and sold them alongside a range of extremely unhealthy cakes and snacks and it was not possible to ascertain the extent to which customers chose the healthier alternatives instead of the unhealthy options.

According to the public health officials interviewed, the businesses could easily be persuaded to add diet drinks and fruit juices to their drinks offering (criterion 14) as this only involved making shelf space for these alternatives. Many were also persuaded to re-arrange the displays in their drinks cabinets so that these healthier varieties were displayed at eye level. Changing the choice architecture in this way has been found to influence purchasing behaviour in other retail and catering environments (Thaler and Sunstein 2008). However the businesses interviewed for this study reported that most customers had well established preferences which could not be influenced in this way, suggesting that whilst this strategy may work in some settings, such as supermarkets, and with younger children, it may be harder to change more established adult preferences.

In contrast, persuading businesses to offer fresh fruit and wholegrain varieties of carbohydrates (criteria 18 and 20) was much harder. Sixteen and 19 of the businesses respectively did not want to provide these healthier alternatives. Interviews with businesses found a greater resistance from those located in the less affluent areas. Two had been willing to give these healthier alternatives a try but had found that they had not been popular with customers and the fresh fruit or wholemeal bread had had to be thrown away. Healthier alternatives were not so popular with customers, particularly if they were more expensive. As the businesses explained:

Three years ago we listed fruit salad on the menu - no one wanted it. At every corner there is a fruit stall open late so people would rather buy from them (kebab house).

I have tried using baby spinach and beetroot in salads which costs more, but my customers have told me that they prefer not to have healthier options rather than pay more (sandwich bar). 
Thus, even where business owners were highly committed to offering healthier menus, they were constrained from doing so by lack of demand and the need to keep prices affordable.

Businesses operating in more affluent areas were more willing to adopt the healthier alternatives, as they identified a market for healthier food in their area. 'People in this area are more health conscious' reported one cafe owner. There were no problems selling wholegrain varieties in these middle class areas.

Offering lower fat spreads and dressings (criterion 10) met with the greatest resistance ( 22 businesses) and the interviews suggested that this may be partly due to the problem of sourcing these from mainstream suppliers. Other studies have also noted that many catering outlets are restricted by having to choose their supplies from what is in the wholesalers' catalogues (NEF 2010).

The scheme managed to persuade 15 businesses to offer smaller portions for children (criterion 21), but the interviews suggested that whilst businesses were willing to provide these when asked, they were less keen to actively promote them as they feared that the reduced price that would have to be charged would lead to a decrease in profits.

Practical operational issues therefore, as well as differing cultural practices and the actual or perceived impact of the changes on profits, are likely to influence businesses' willingness to offer healthier alternatives.

\section{Guiding choice by changing the default policy}

Two of the HCC criteria (criteria 12 and 13) sought to reduce salt consumption by changing the default policy regarding the use and availability of salt. Allowing customers to add their own salt (criterion 12) proved to be one of the criteria which was most readily adopted by the businesses with 20 agreeing to make this change and none refusing to do so. One restaurant interviewed removed the salt shakers from the tables and found customers rarely asked for them. 'Salt shakers are behind the counter now and very few customers ask for them', he reported. During the focus group discussion it was suggested that this was an easy change to persuade businesses to make because, 'Everyone is aware of the dangers of salt.' Thus this criterion provides a classic example of an intervention that is easy to sell to businesses since knowledge of the dangers of salt is widespread, it costs the business nothing, and can be introduced with a crafty bit of change to the choice architecture.

Persuading businesses not to add salt to the water used for cooking food (criterion 13) proved to be much harder, with only seven businesses agreeing to make this change and 25 being unwilling to do so. The interviews suggested that businesses were concerned that not adding salt would radically alter the taste of the food and would result in a loss of customers.

\section{Eliminating choice}

The first eight HCC criteria (criteria 1 to 8) could be classified as eliminating choice. These included the four essential criteria regarding the use of oil. The scheme successfully persuaded 12 businesses to switch to a healthier type of oil for cooking (criterion 3) and also had a good degree of success in encouraging businesses involved in deep-fat frying to adopt healthier practices regarding the use and maintenance of their cooking oil (criteria 5, 6, and 7). Adopting these criteria concerned changes which 
could be made without incurring significant extra costs for most businesses and which were unlikely to be rejected by customers. In fact most went unnoticed. Twenty-three of the 28 customers surveyed had not noticed the change and the three that had were quite happy with it. However most of the businesses interviewed for this study only fried a small proportion of their menu items, and thus the extra $15 \%$ cost of a healthier variety of oil could be relatively easily absorbed. For those whose menus involve a significant amount of deep-fat frying, such an increase in costs becomes more significant.

Changing the oil used in the preparation of food (criterion 4) met with more resistance. Four agreed to make the change but 10 resisted. Interviews with those administering the scheme suggested that outlets which take pride in using traditional ingredients associated with particular cuisines were reluctant to change what they viewed as being an integral aspect of classic menus that are popular with customers. Offering thick-cut chips (criterion 19) which absorb less fat than thinner versions was also rejected by 12 of the businesses although five did agree to make this change. This is clearly a change that customers are likely to notice and thus cost and customer preferences are an issue for businesses to consider. Interviews with businesses suggested that these changes are more readily accepted in some areas than others, with those operating in more disadvantaged areas finding it harder to persuade customers to buy the healthier variety. 'I explain the health benefits of thicker chips to customers but they don't care', stated one business. This finding echoes that from research for the Food4Health award scheme in Tower Hamlets, London, one of the most deprived areas in the UK. This found considerable resistance from fast food businesses operating at the lower end of the market to making even small changes - offering fatter-cut chips and smaller portions for example, for fear it would result in a loss of customers and income (Bagwell 2011, Sanderson 2012).

\section{Discussion}

Government policy is concerned that people should be assisted in making healthier choices - either by being given better information and healthier alternatives or perhaps through gentle nudges. In general, restricting choice is seen as a last resort - a strategy only to be used if the benefits outweigh the resulting loss of individual freedom. At the same time, policy is also concerned to address health inequalities and this presents a challenge for initiatives designed to encourage healthier catering and consumption practices.

The research presented here, whilst clearly a small-scale study, suggests that the less intrusive interventions which sought to change consumption behaviour by the provision of information on healthier food and by offering healthier alternatives, resulted in the provision of healthier food for some. These tended to be the more affluent, and often already more health-conscious customers however, who were able and willing to pay the extra costs involved. The healthier alternatives were positively resisted in some of the more deprived communities, particularly where they resulted in increased prices. Businesses in these less affluent areas are often struggling to survive in a highly competitive and very price-sensitive marketplace, and are not willing to make changes that are seen as not financially viable. Thus it seems that the healthier alternatives promoted by healthier catering schemes may well be improving the health of the already more health-conscious middle classes, but are unlikely to be having much of an impact on the more disadvantaged members of our society. In fact by improving the health of those that can afford to take advantage of these healthier choices they are possibly unwittingly widening the gap in health inequalities. 
Nudges, such as changing the default policy so that healthier alternatives are always provided unless customers ask otherwise, may be more effective and meet with less resistance from the businesses surveyed here. Moving the salt shakers behind the counter was one such example. However this may well have been successful because it was re-enforcing a well-established public health message. Thus, as others have suggested, nudges have their place but need to be part of overall policy-making rather than being viewed as a novel alternative (Dolan et al. 2010, Kessel and Allmark 2011). A reliance on nudging approaches may also encourage government to shed its regulatory responsibilities (Rayner 2011). Furthermore the capacity of 'nudge' approaches to ensure the affordability of healthy food is also extremely questionable (Dowler et al. 2011).

In many areas it is only more intrusive interventions which guide choice by disincentives, or restrict or eliminate choice, that are likely to be effective. Even here simple changes like changing the type of oil or spread used is difficult for those businesses operating on the margins of survival and who are tied into using suppliers who charge premium prices for healthier varieties. In less affluent communities the extra costs of such healthier varieties cannot be passed on to the customer and thus present a real threat to the viability of the business. In these areas the cheapest products will be bought unless legislation is introduced to prevent their use.

The suppliers of these micro enterprises are not involved in any national Responsibility Deals, but need to be encouraged to sell healthier products and reduce the price differential between healthy and unhealthy varieties. If voluntary agreements fail however, government needs to step in and take action - for example by banning the use of oil high in saturated and trans fats by those involved in deep fat frying. This would at least, providing it could be enforced, put all businesses on a level playing field and force suppliers to provide healthier alternatives. Until then, healthier catering initiatives are likely to have a limited impact on the health of those in the most disadvantaged areas and communities and food poverty in these areas will persist.

\section{Acknowledgements}

This paper incorporates the findings of a research project commissioned by the Greater London Authority and the Chartered Institute for Environmental Health, and a further related study commissioned by the Inner North West London Primary Care Trusts. I am grateful to Simon Doff and Antje Witting of London Metropolitan University for their involvement in the research.

\section{References}

Bagwell, S. 2011. The role of independent fast-food outlets in obesogenic environments: a case study of East London in the UK. Environment and Planning A, 43 (9), 2217-2236.

Chaufan, C., Fox, P., and Hee Hong, G. 2011. Food for thought: menu labeling as obesity prevention public health policy. Critical Public Health, 21 (3), 353-358

$\mathrm{CIEH}, 2004$. The heartbeat award scheme consultation, London: Chartered Institute for Environmental Health.

Coveney, J., 2003. Why food policy is critical to public health. Critical Public Health, 13 (2), 99-105.

Cross-Government Obesity Unit, 2008. Healthy Weight, Healthy Lives A Cross Government Strategy for England, London: Department of Health and Department of Children, Schools and Families.

Currie J., et al, 2009. The effect of fast food restaurants on obesity. The National Bureau of Economic Research, 1050 Massachusetts Avenue, Cambridge, MA.

DEFRA, 2012. Family Food 2011, London: Department for Environment Food and Rural Affairs. 
Department of Health (DoH), 2011. Healthy Lives, Healthy People; A call to action on obesity in England. HMSO 16166.

De Vogli, R., Kouvonen, A., and Gimeno, D. 2011. 'Globesization': ecological evidence on the relationship between fast food outlets and obesity among 26 advanced economies. Critical Public Health, 21 (4), 395-402.

Dolan, P. et al., 2010. MINDSPACE: Influencing behaviour through public policy. UK Cabinet Office and Institute for Government

Dowler, E. et al., 2011, Thinking about 'food security': engaging with UK consumers. Critical Public Health, 21 (4) 403-416.

Elbel, B., et al., 2009. Calorie labeling and food choices: a first look at the effects on lowincome people in New York City. Health Affairs, 28(6), 1110-21.

FAO, 1996. Rome declaration on world food security. World Food Summit, 13-17 November 1996. Rome: FAO

Fraser, L., et al., 2010. The geography of fast food outlets: a review. International Journal of Environmental Research and Public Health, 7 (5), 2290-2308.

Foresight, 2007. Tackling Obesities: Future Choices Government Office of Science, London: Department for Science.

Gustafsson, U., Wills, W., and Draper, A. 2011. Food and public health: contemporary issues and future directions. Critical Public Health, 21 (4) 385-393.

Holdsworth, M., Raymond, N., and Haslam, C., 2004. Does the Heartbeat Award scheme in England result in change in dietary behaviour in the workplace? Health Promotion International, 19 (2), 197-204.

House of Lords, 2011. Behaviour Change. House of Lords Science and Technology Select Committee: 2nd Report of Session 2010-12, London, House of Lords.

Kessel, A., and Allmark, P. 2011 Déjà vu: Groundhog day for public health policy? in Nudge politics. Food Ethics, Food Ethics Council. 6 (1) 10-11.

Kwate, N., 2008, Fried chicken and fresh apples: Racial segregation as a fundamental cause of fast food density in black neighbourhoods" Health \& Place, 14 32-44.

LACORS, 2010. Healthier Catering Awards LACORS landscaping paper, January 2010. London: Local Authorities Coordinators of Regulatory Services.

LHO/NEHO 2010, Index of Multiple Deprivation 2010: summary scores for 2010 electoral wards and Index of Multiple Deprivation 2010: summary scores for local authorities. Available from www.apho.org.uk/resource/view.aspx?RID=111280 (Accessed 16th December 2012).

Lindsay, J. 2010. Healthy living guidelines and the disconnect with everyday life. Critical Public Health 20(4), 475-487.

London Borough of Barking and Dagenham, 2009. Saturation Point: Addressing the health impacts of hot food takeaways: Draft Supplementary Planning Document. London Borough of Barking and Dagenham.

London Borough of Waltham Forest, 2008. Waltham Forest SPD- Hot food Takeaway Shops (Consultation Draft), Spatial Planning Unit, London Borough of Waltham Forest.

Macdonald, L., Cummins, S., and Macintyre, S. 2007. Neighbourhood fast food environment and area deprivation-substitution or concentration? Appetite, 49(1): 251-254.

Marmot, M. 2010. Fair Society, Healthy Lives: The Marmot Review: Strategic Review of Health Inequalities in England Post 2010. University College London.

NEF, 2010. An inconvenient sandwich: the throwaway economics of takeaway food. London: New Economics Foundation.

Pearce J., et al., 2007. Neighbourhood Deprivation and Access to Fast-Food Retailing A National Study. American Journal of Preventive Medicine, 32(5): 375-382.

Pereira M. el al., 2005, Fast-food habits, weight gain, and insulin resistance (the CARDIA study): 15-year prospective analysis. The Lancet 365, (9453) 36-42.

Prentice A M, Jebb S A, 2003, Fast foods, energy density and obesity: a possible mechanistic link. Obesity Review, 4 (4) 187-94. 
Rayner, G., 2011 Nudge public health: the new laissez-faire? in Nudge politics, Food Ethics, Food Ethics Council. 6 (1) 7-8.

Sanderson, M., 2012. Tower Hamlets Food for Health Award Project: March 2009- March 2012: Draft final Evaluation Report. Tower Hamlets Primary Care Trust.

Seex, P., 2007, Business investment in deprived areas: Creating the conditions. Journal of Urban Regeneration and Renewal, 1 (2) 119-128.

Smoyer-Tomic, K., el al 2008. The association between neighbourhood socioeconomic status and exposure to supermarket and fast food outlets. Health \& Place 14 (4) 740-754.

Thaler, R. and Sunstein, C., 2008. Nudge: Improving Decisions About Health, Wealth, and Happiness. New Haven, Yale University Press.

Thorogood, M. et al, 2007. A systematic review of population and community dietary interventions to prevent cancer. Nutrition Research Reviews, 20, 1-16.

Wallop, H, 2012. Fast food becomes the UK's meal of choice, The Telegraph, 15th January

Table 1. Business take-up of the HCC Criteria

\begin{tabular}{|c|c|c|c|c|c|c|}
\hline & & Number of b & usinesses wl & iere... & & \\
\hline & Criterion & \begin{tabular}{|l|} 
Criteria \\
already \\
fulfilled \\
PRIOR to \\
intervention
\end{tabular} & $\begin{array}{l}\text { Criteria } \\
\text { fulfilled } \\
\text { AFTER } \\
\text { advice/ } \\
\text { interventi } \\
\text { on }\end{array}$ & \begin{tabular}{|l|} 
Business \\
does not \\
want to \\
change
\end{tabular} & $\begin{array}{l}\text { Not } \\
\text { applicable }\end{array}$ & $\begin{array}{l}\text { Nature of } \\
\text { intervention }\end{array}$ \\
\hline & 1. Fat removed from meat before cooking & 50 & 4 & 7 & 16 & $\begin{array}{l}\text { Eliminates } \\
\text { choice }\end{array}$ \\
\hline & 2. Food is grilled or baked not fried & 61 & 4 & 6 & 6 & $\begin{array}{l}\text { Eliminates } \\
\text { choice }\end{array}$ \\
\hline $\mathbf{E}$ & $\begin{array}{l}\text { 3. Polyunsaturated or monounsaturated } \\
\text { fat or oil used for cooking }\end{array}$ & 63 & 12 & 0 & 2 & $\begin{array}{l}\text { Eliminates } \\
\text { choice }\end{array}$ \\
\hline & $\begin{array}{l}\text { 4. Polyunsaturated or monounsaturated } \\
\text { fat or oil used for preparation }\end{array}$ & 54 & 4 & 10 & 9 & $\begin{array}{l}\text { Eliminates } \\
\text { choice }\end{array}$ \\
\hline $\mathbf{E}^{*}$ & $\begin{array}{l}\text { 5. Cooking oil in deep fat fryers heated to } \\
\text { optimum temperature }\end{array}$ & 45 & 15 & 0 & 17 & $\begin{array}{l}\text { Eliminates } \\
\text { choice }\end{array}$ \\
\hline $\mathbf{E}^{*}$ & $\begin{array}{l}\text { 6. Excess fat drained from food before } \\
\text { serving }\end{array}$ & 50 & 10 & 0 & 17 & $\begin{array}{l}\text { Eliminates } \\
\text { choice }\end{array}$ \\
\hline $\mathbf{E}^{*}$ & 7. Oil in fryer is properly maintained & 51 & 8 & 0 & 18 & $\begin{array}{l}\text { Eliminates } \\
\text { choice }\end{array}$ \\
\hline & 8. Chips are thick cut & 34 & 5 & 12 & 26 & $\begin{array}{l}\text { Eliminates } \\
\text { choice }\end{array}$ \\
\hline & $\begin{array}{l}\text { 9. Semi skimmed or skimmed milk is } \\
\text { available for drinks }\end{array}$ & 51 & 6 & 5 & 15 & $\begin{array}{l}\text { Enables } \\
\text { choice }\end{array}$ \\
\hline & $\begin{array}{l}\text { 10. Lower fat spreads, mayonnaise and } \\
\text { dressings are available }\end{array}$ & 31 & 10 & 22 & 14 & $\begin{array}{l}\text { Enables } \\
\text { choice }\end{array}$ \\
\hline & $\begin{array}{l}\text { 11. Where sandwiches served at least } 2 \\
\text { lower fat fillings are available }\end{array}$ & 34 & 1 & 3 & 39 & $\begin{array}{l}\text { Enables } \\
\text { choice }\end{array}$ \\
\hline
\end{tabular}




\begin{tabular}{|c|c|c|c|c|c|c|}
\hline $\mathbf{E}$ & $\begin{array}{l}\text { 12. Customers can add own salt: Sachets } \\
\text { or salt shakers with fewer holes available }\end{array}$ & 51 & 20 & 0 & 6 & $\begin{array}{l}\text { Guides } \\
\text { choice by } \\
\text { changing } \\
\text { default } \\
\text { policy }\end{array}$ \\
\hline & $\begin{array}{l}\text { 13. Salt not added to water used for } \\
\text { cooking veg, rice \& pasta }\end{array}$ & 29 & 7 & 25 & 16 & $\begin{array}{l}\text { Guides } \\
\text { choice by } \\
\text { changing } \\
\text { default } \\
\text { policy }\end{array}$ \\
\hline \multirow[t]{7}{*}{$\mathbf{E}$} & $\begin{array}{l}\text { 14. If soft drinks sold, water, reduced } \\
\text { sugar/diet drinks and /or unsweetened } \\
\text { fruit juice are available }\end{array}$ & 63 & 13 & 0 & 1 & $\begin{array}{l}\text { Enables } \\
\text { choice }\end{array}$ \\
\hline & $\begin{array}{l}\text { 15. Lower sugar snacks are available as } \\
\text { alternative to biscuits, chocolate etc }\end{array}$ & 22 & 7 & 9 & 39 & $\begin{array}{l}\text { Enables } \\
\text { choice }\end{array}$ \\
\hline & 16. Drinking tap water is always available & 55 & 2 & 6 & 14 & $\begin{array}{l}\text { Enables } \\
\text { choice }\end{array}$ \\
\hline & $\begin{array}{l}\text { 17. A portion }(80 \mathrm{~g}) \text { of veg or salad is } \\
\text { always available as an accompaniment }\end{array}$ & 64 & 7 & 1 & 5 & $\begin{array}{l}\text { Enables } \\
\text { choice }\end{array}$ \\
\hline & $\begin{array}{l}\text { 18. Fresh fruit is always available and } \\
\text { prominently displayed }\end{array}$ & 29 & 3 & 16 & 29 & $\begin{array}{l}\text { Enables } \\
\text { choice }\end{array}$ \\
\hline & $\begin{array}{l}\text { 19. If chips are served there is always a } \\
\text { healthier starchy alternative }\end{array}$ & 39 & 1 & 9 & 28 & $\begin{array}{l}\text { Enables } \\
\text { choice }\end{array}$ \\
\hline & $\begin{array}{l}\text { 20. Wholegrain varieties of carbohydrates } \\
\text { are available. Where rice is served, } \\
\text { boiled/steamed rice is available as an } \\
\text { alternative }\end{array}$ & 46 & 3 & 19 & 9 & $\begin{array}{l}\text { Enables } \\
\text { choice }\end{array}$ \\
\hline \multirow[t]{2}{*}{$\mathbf{E}$} & $\begin{array}{l}\text { 21. Smaller portions are available for } \\
\text { children }\end{array}$ & 60 & 15 & 2 & 0 & $\begin{array}{l}\text { Enables } \\
\text { choice }\end{array}$ \\
\hline & 22. Healthy eating is promoted by staff & 25 & 26 & 20 & 6 & $\begin{array}{l}\text { Provides } \\
\text { information }\end{array}$ \\
\hline
\end{tabular}

$\mathrm{E}=$ essential criteria. $\mathrm{E}^{*}=$ additional essential criteria for those involved in deep-fat frying. 


\section{Notes}

${ }^{\text {i }}$ Email communication from Lucy Green at the NPD Group stated that, 'The NPD Group tracks the UK foodservice market continuously via it's CREST service and can identify trends such as the growth of fast food eating out occasions.'

ii The Index of Multiple Deprivation (IMD) combines a number of indicators, chosen to cover a range of economic, social and housing issues, into a single deprivation score for each small

area in England. The higher the score the greater the level of deprivation. (LHO/NEHO 2010) 